\title{
HVDC: Energia elektrikoaren garraioa korronte zuzenaren bidez
}

\author{
(HVDC: High Voltage Direct Current Power \\ Transmission)
}

Iñigo Martinez de Alegria*, Jon Andreu, Iñigo Kortabarria

APERT ikerketa-taldeko ikertzailea UPV/EHU

* inigo.martinezdealegria@ehu.eus

DOI: 10.1387/ekaia.16444

Jasoa: 2016-06-03

Onartua: 2016-10-03

Laburpena: Nahiz eta energia elektrikoaren garraio-sareak korronte alternoan lan egin, Tentsio altuko korronte zuzena (HVDC edo high-voltage direct current) korronte zuzeneko sistema alternatiba eraginkorra da oso distantzia luzeko eta potentzia handiko energia elektrikoaren garraiorako, itsasoan sortutako energia lurrera garraiatzeko eta beste hainbat aplikazio berezitarako. Etorkizuneko energia berriztagarrietan oinarritutako sistema elektrikoaren lagungarri handia eta ezinbestekoa izango da HVDC teknologia.

Hitz-gakoak: HVDC, artezgailua, potentzia erdieroaleak.

Abstract: Most of the electric power transmission system uses AC to deliver power, but HVDC (high-voltage direct current) is becoming a very important alternative for very log distance power delivery, offshore transmission systems and underground cable systems. HVDC will play a ma jor role in the integration of renewable energy in the electric power system.

Keywords: HVDC, rectifier, power semiconductors.

\section{SARRERA}

Energia elektrikoa KA edo korronte alternoaren forman garraiatu eta gure lantegi eta etxeetara heltzen da. Honen arrazoia garraioan gertatzen diren potentzia-galerak txikitzean datza. Potentzia jakin bat eramateko kableetan dauden galera ohmikoak korrontearekin era kuadratikoan handitzen dira $\left(P=R I^{2}\right)$ eta, beraz, garraioan tentsio oso altuak erabili behar dira korrontea gutxitzeko. 
KA sistemetan tentsioa handitu edo txikitzea sinplea da. Transformadorea erabiliz, tentsioa handitu eta txikitu daiteke isolamendu maila handiarekin eta galera gutxirekin. Oso dispositibo sinplea da eta mantenimendu gutxi behar duena. Gainera, KA sorgailu trifasikoa KZ edo korronte zuzeneko sorgailua baino askoz eraginkorragoa da ikuspegi guztietatik.

Kaleak argiztatzeko 1870eko hamarkadaren amaieran tentsio altuko korronte alternoaren sistema erabiltzen hasi zen. 1882an, Thomas Edisonek etxeetan eta enpresa txikitan olio eta gasaren ordez korronte zuzeneko argi elektriko sistema bat komertzializatu zuen. 1886. urtean George Westinghousek transformadoreak erabiliz tensio altuagoko korrente alternoko sistemak garatu zituen, galerak nabarmenki gutxituz. Honek korronte elektrikoa garraiatzeko distantziak handitzea ahalbidetu zuen, gero transformadoreen bidez berriro tentsioa gutxituz etxeetan erabiltzeko. Westinghousen sistemak kolokan jarri zuen Edisonen negozioa. KA sistemak arriskutsuak zirela argudiatuz, tentsio altu hilgarriak eta jesarleku elektrikoa politikoki erabiliz, Edisonek KA sistemak bertan behera uzteko kanpaina zabaldu zuen, «korronteen gatazka» esaten zaion prozesuan. Azkenean KA sistema gailendu zen garraio-distantzia luzeak eta koste baxuak lortzen zirelako.

Arrazoi hauengatik jada XIX. mendetik, Westinhousek Edisonekin korronteen gatazka irabazi zuenetik, transformadorea erabiliz garraio-tentsio oso handiak lortzeko, KZ sistemak oso gutxitan erabili izan dira energia elektriko kantitate handiak garraiatzeko.

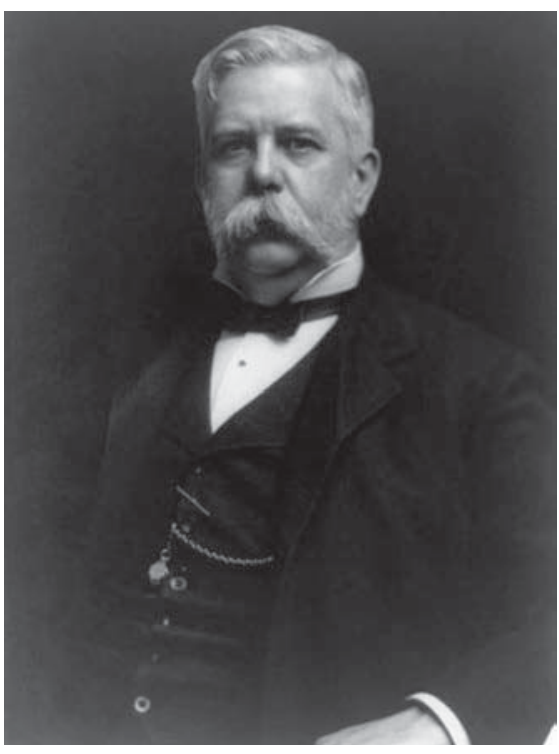

a) George Westinghouse

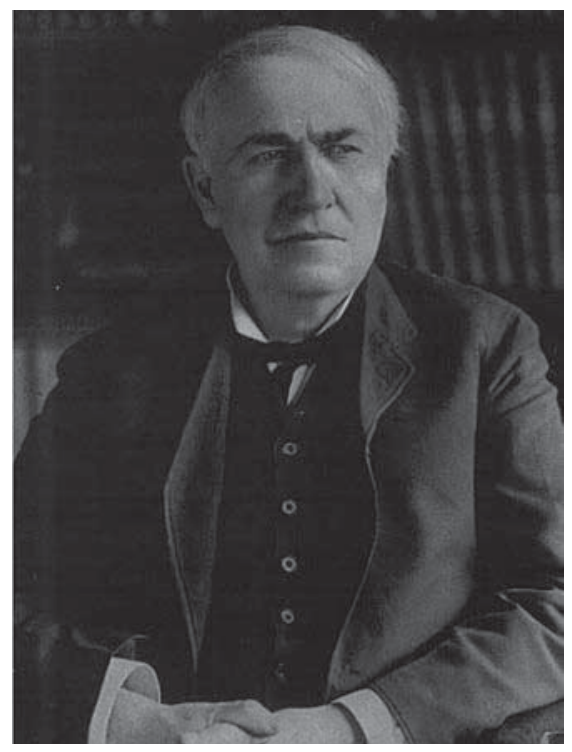

b) Thomas Edison

1.irudia. KA eta $\mathrm{KZ}$ sistemen aitzindariak. 
Energia elektriko gehiena KA moduan sortzen da, baina zergatik izaten da hobe batzuetan HVDC moduan garraiatzeta?

Galdera interesgarria da, garraio gehiena hiru faseko KA sistemetan gertatzen baita. Zer onura ekar dezake KZ moduan energia elektrikoa garraiatzeak gaur eguneko sare elektrikoan?

Nahiz eta KA sistema izan elektrizitatea garraiatzeko era erabiliena azken ehun urteetan, korronte alternoak gaindiezinezko muga batzuk ditu energia kantitate handiak garraiatzeko: alde batetik, garraio-distantzia luzeegia denean KA sistema baten potentzia-galerak KZ sistema batenak baino askosaz altuagoak dira, eta, bestetik, lurpean edo itsasondoan eroale hutsa erabili beharrean kableak ${ }^{1}$ erabili behar direnean, KA sisteman korronte erreaktiboa handiegia izaten da eta $\mathrm{KZ}$ sistema erabili behar da askotan.

Energiaren paradigma-aldaketarekin eta sare inteligenteagoa eraikitzeko ahalegin honetan, HVDCk gaur arte izan duena baino garrantzia handiagoa hartuko du korronte alternoko sarea konplementatzen. Adibidez, gaur egun HVDC da itsasotik energia elektrikoa lurrera garraiatzeko metodorik hautatuena eta korronte alternoko sare asinkrono ezberdinen arteko loturak egiteko modurik egokiena. Orobat, HVDC da distantzia oso luzeko energia elektriko kantitate handiak garraiatzeko teknologiarik egokiena, energia-galera minimoekin garraiatzeko gai baita. Ahalmen honek aukera ematen du kontsumitzaileengandik oso urrun dauden energia berriztagarriak garraiatzeko.

Korronte alternoaren ordez HVDC aukeratzea kasu jakinetan arrazoi konplexu askorengatik izan daiteke. Batzuetan teknikoki desiragarria da sarearen kontrolabilitatea handitzeko, beste batzuetan, ekonomikoki, inbertsioa osotasunean merkeagoa izan daiteke galerak kontuan hartuta, eta beste batzuetan ingurunerako egokiagoa gertatzen da. Gehienetan HVDC loturak arrazoi tekniko, ekonomiko eta ingurunekoen konbinazio sorta batez justifikatuta daude.

\section{HVDCren HISTORIA LABUR BAT}

HVDCren ikuspegi teknikoa landu aurretik, historian zehar teknologia honek eduki duen lekua aztertuko da atal honetan.

KZ sisteman, mutur batean KA tentsioa arteztu eta korronte zuzena lortu, eta beste muturrean korronte zuzen hori berriro korronte alternora pasatzeko gaitsuna beharrezkoa da. Gainera, prozesu hau oso tentsio altuetan gertatu behar da garraioa eraginkorra izateko.

\footnotetext{
1 Kablea: isolatzaile batez inguratutako eroalea.
} 
Izatez, energia elektrikoaren garraio eta banatzea korronte zuzeneko sistemekin hasi zen. 1882. urtean, $50 \mathrm{~km}$-ko eta $2 \mathrm{kV}$-eko korronte zuzeneko transmisio-sistema eraiki zen Miesbach-en eta Munich-en artean, Alemanian. Garai horietan tentsioaren handitzea korronte zuzeneko makina birakariekin bakarrik egin zitekeen.

1920ko hamarkadan, Calverley eta Hardfieldek «transverter» izeneko sistemarekin saiatu ziren, hainbat transformadore era sinkronoan eta eskuilak erabiltzen zituen artezgailu batean oinarrituta.

Merkurio arkuko artezgailuak asmatu zirenean, 1930eko hamarkadan, artezgailu eta inbertsore estatikoekin ${ }^{2}$ saiatu ziren lehenengo aldiz, eta 1940. urtera arte Amerikan tiratroia eta Europan merkuriozko balbula erabiliz hainbat artezgailurekin saiatu ziren.

Suedian, Estatu Batuetan eta Sobietar Batasunean distantzia oso handiak daudenez, herrialde hauek oso interesatuta agertu ziren HVDC sistemak garatzeko. Sobietar Batasunean anodo bakarreko balbula bat erabili zen II. Mundu Gerra garaian, eta Suedian Allmana Svenska Elektriska Aktiobologet (ASEA) enpresak ikerketa-ahalegin handiak egin zituen 1940tik aurrera. Alemaniako kasuan, sare elektrikoa bonbardaketetik babesteko lurpeko kableak seguruak izango zirelakoan, Berlinen Charlotenburg eta Moabit lotzen zuen $115 \mathrm{~km}, 60 \mathrm{MW}$ eta $400 \mathrm{kV}$-eko HVDC sistema bat eraiki zen, baina martxan jarri aurretik, Sobietar armadak Berlin hartu zuen eta sistema Sobietar Batasunera eraman zuen.

1945etik aurrera Sobietar Batasunak balbulen ikerketa berrartu zen eta Mosku eta Kashira arteko 112 km, 30 MW eta 200 kV-eko HVDC sistema bat eraiki zuen [1].

Hala ere, Suedian, eta bereziki Udo Lamm, dira HVDC sistemaren garapenean pausorik garrantzitsuena eman zutenak, bi korronte alternoko sistemak (Gotland uharteko eta Suediako sistemak) lotzean $50 \mathrm{~km}, 20 \mathrm{MW}$, eta $100 \mathrm{kV}$ ko HVDC sistema bat erabiliz 1954an [2]. Horren ondoren, ASEAk la Manchako ubidean, Konti-Skan, Suedia-Danimarka, Sakuma, Zelanda Berria eta Italia-Sardiniako HVDC transmisio-sistemak eraiki zituen merkuriozko balbulak erabiliz.

Hurrengo urrats garrantzitsua 1967an eman zen, Gotland-eko sisteman merkuriozko balbula tiristore balbula erieroalez (tiristoreak material erdieroalez egindako artezgailuak dira) ordezkatzean.

Hurrengo aurrerapausu adierazgarria 1997. urtean eman zen ABBk Hällsjönen, Suedian, lehenengo aldiz HVDC VSC IGBT erdieroaleen bi-

\footnotetext{
2 Artezgailu/inbertosre estatikoak: Mugimentu mekanikorik gabeko artezgailu/inbertsoreak.
} 
dezko teknologia erabili zuenenean. Lehenego saiakera honetan, $10 \mathrm{~km}-\mathrm{ko}$ $3 \mathrm{MW}$ eta $\pm 10 \mathrm{kV}$-eko sistemarekin saiatu ziren, baina ordutik hona teknologia honek HVDC erabilpenaren hedapena ahalbidetu du, hurrengo ataletan ikusiko den bezala.

Azken urteotako aurrerapen tekniko nagusiena HVDC VSC teknologian 2 mailako bihurgailuak MMC bihurgailuez ordezkatzea izan da. MMC potentzia-bihurgailudun lehenengo HVSC VSC sistema komertziala 2010. urtean eraiki zen, San Francisco hiriko badiaren bi muturren arteko kablea instalatzeko (Trans bay cable).

Ordutik hona, potentzia-erdieroaleen garapenarekin batera eman dira HVDC sistemen aurrerapausu handienak, eta HVDC sistemen kopurua munduan asko handitu da.

1 taulak HVDC garapenaren gertaera nagusiak erakusten ditu.

1. taula. HVDCren historia.

\begin{tabular}{c|l}
\hline 1882 & $\begin{array}{l}\text { Lehen luzera handiko «HVDC» sistema, 57 km (Miesbach-Munich), 1.4 kV. } \\
\text { Oskar von Miller eta Marcel Deprez. }\end{array}$ \\
\hline $1890-1910$ & $\begin{array}{l}\text { HVDC sistema elektromekanikoak. } \\
70-200 \mathrm{~km}, 6-60 \mathrm{kV}, \leq 4.5 \mathrm{MW} .\end{array}$ \\
\hline $1935-1944$ & $\begin{array}{l}\text { Merkurio balbularen garapenak HVDC LCC sistemen diseinua ahalbidetu } \\
\text { zuen. } \\
\text { Hainbat sistema instalatu ziren, Hanover, Wettingen, Zurich eta Berlinen adi- } \\
\text { bidez. } \\
30 \text { km, 50-100 kV, 5-40 MW inguruko sistemak dira. }\end{array}$ \\
\hline 1945 & $\begin{array}{l}\text { Lehen kable bidezko HVDC proiektua Berlinen. } \\
\pm 200 \mathrm{kV}, 60 \mathrm{MW}, 115 \text { km, Siemens eta AEG. } \\
\text { II Mundu Gerra amaieran errusiarrek desmontatu eta Moskura eraman zuten. }\end{array}$ \\
\hline $1951-1954$ & $\begin{array}{l}\text { Lehen HVDC komertzialak merkuriozko balbulekin: Kashira-Mosku HVDC } \\
100 \mathrm{~km}, \pm 100 \mathrm{kV}, 30 \text { MW. } \\
\text { Gotland 100 kV 20 MW 98 km. }\end{array}$ \\
\hline $1975-1979$ & $\begin{array}{l}\text { Lehen HVDC LCC tiristoreekin. } \\
\text { Cahora Bassa, Mozambique-South Africa. } \\
1.414 \mathrm{~km}, \pm 533 \mathrm{kV}, 1.920 \text { MW (Siemens, AEG eta BBC). }\end{array}$ \\
\hline 1997 & $\begin{array}{l}\text { Lehen HVDC VSC sistema (Hellsjon, Suedia). } \\
\text { Lehen MMC teknologiaren bidezko HVDC VSC. }\end{array}$ \\
\hline
\end{tabular}




\section{HVDCren ABANTAILAK}

HVDC gaur egun frogatutako teknologia da eta hainbat abantaila tekniko ekartzen dizkio sare elektrikoari, eta zenbait aplikaziotan aukera bakarra da korronte alternoak dituen limitazioengatik. Adibidez, oso distantzia luzeko $(1.000 \mathrm{~km})$ energia elektriko kantitate handiak ezin dira era ekonomikoan korronte alternoan eraman, tentsio-erorketa eta galera handiegiak direlako. Korronte alternoko maiztasun ezberdineko sareak ezin dira elkar lotu HVDC lotura bat ez bada erabiltzen (gainera, HVDC sistemak potentziaren fluxuaren berehalako kontrol oso zehatza ahalbidetzen du).

\subsection{HVDCren abantaila teknikoak}

Hurrengo lerroetan HVDCaren abantaila tekniko nagusiak zehazten dira:

\section{Sare elektriko asinkronoen arteko lotura}

KA sistema ezberdinak zuzenenan lotzeko (adibidez, sarea indartzeko edo sistemen arteko energiaren salerosketa ahalbidetzeko), hauek sinkronizatuta egon behar dira.

Honek tentsio eta maiztasun berdinean lan egitea esan nahi du eta hau lortzea oso zaila izan daiteke, ezengonkortasuna sor daitekeelako, zirkuitu laburren korronteak handiegiak izango lireketeelako edo energia-fluxu ezkontrolatuak gertatu daitezkeelako.

HVDC asinkronoa denez, edozein maiztasuneko bi KA sistema lotzeko erabil daiteke. Hau munduko hainbat lekutan erabili da banatutako sistema elektriko oso handiak elkarrekin lotzeko. Adibidez, Eskandianabiako Nordel eta Europako UCTE sistemak, eta Estatu Batuetako ekialde eta mendebaldeko sistemak maiztasun berdina erabiltzen dute baina ez daude sinkronizatuta, eta Japonia eta Sudamerikan hainbat sistemak maiztasun ezberdinak erabiltzen dituzte. Sistema hauek lotzeko HVDC teknologia erabili da.

Oso distantzia luzeko energia elektrikoaren garraioa eta urpeko kableen bidezko konexioak

Korronte- eta isolamendu-baldintza berdinetan HVDCk \% 40 energia gehiago garraiatu dezake $\% 30$ potentzia-galera gutxiagorekin; horregatik, oso distantzia luzeetan (800 km-tik gora) ekonomikoki merkeagoa da HVDC erabiltzea. KA kableen bidezko transmisioan, kablearen kapazitatearen korronte erreaktiboa korronte aktiboari gehitzen zaio eta honek kablearen luzeera maximoa mugatzen du. KZ sistema batean, ordea, ez dago 
honelako mugarik eta edozein luzerako kablea erabil daiteke teorikoki, arrazoi honegatik, batzuetan HVDC da erabili daitekeen bakarra izaten da. Adibidez, itsasoan instalatutako sistema batean $50 \mathrm{~km}$ ingurutik gorako distantzietan HVDC izaten da aukera tekniko bakarra. Adibididez, NorNed konexioan, Norbegia eta Holanadaren artean, itsasotik $580 \mathrm{~km}$ luzerako HVDC kable bat erabiltzen da.

\section{Sareen kontrolagarritasunaren hobekuntza}

HVDCk ia instantaneoki kontrolatu dezake potentzia aktiboaren fluxua (HVDC VSC teknologiak gauza bera egin dezake potentzia erreaktiboarekin), eta, beraz, KA sistemetan gertatzen diren oszilazioak moteltzeko oso erabilgarriak izaten dira, maiztasuna konstante mantentzeko, KA sarean potentzia era egokian banatzeko, oszilazioak moteltzeko eta abar. Askotan kontrol gehigarri hau KA linea ezberdinen kapazitatea handitzeko erabil daiteke aurretik estabilitateak mugatuta zeudenean.

\section{Zirkuitulaburreko korrontearen gutxitzea}

Generazio-planta bat KA sarera lotzean KA transmisio erabiliaz, zirkuitulaburreko korrontea handitu egiten da. Zirkuitulaburreko korronte oso altuak gero eta arazo handiagoa bihurtzen ari dira hiri edo populazio handiko guneetan eta askotan beharrezkoa izaten da babes-ekipamendu berriak, handiagoak eta garestiagoak instalatzea.

HVDC sistemak ez du handitzen konektatzen den KA sisteman zirkutu labur korrontea. Energia-sorgaliuak DC sistema baten bidez lotzen badira, zirkutu labur korrontea ez denez handitzen, ez da babes-ekipamendu berria instalatu behar KA aldean.

\subsection{HVDCren abantailak ingurumen eta ekonomia mailan}

HVDC sistemak hainbat kasutan abantaila ekonomiko eta teknikoak ekartzen ditu, eta horretaz gain, ingurumenerako inpaktu gutxiagoko alternatiba izaten dira. Hurrengo lerroetan abantaila nagusienak aipatzen dira.

\section{Bide-zorraren gutxitzea}

HVDC aireko linea bipolar bat, zirkuitu bikoitzeko, KA aire-linea bat bezalakoa da fidagarritasunaren ikuspuntutik. Beraz, bi eroaledun HVDC linea batek ingurumenean inpaktu txikiagoa du 6 eroaleko KA zirkuitu batek baino, espazio gutxiago eta inpakto bisual txikiagoa duelako. HVDC VSC teknologiarekin askotan posible da lurperatutako kableak erabiltzea airetik doazen lineen ordez. 2 irudian potentzia berbera eramateko eta erre- 
dundantzia berbereko KA eta KZ sistemek behar duten bide-zorra erakusten da.

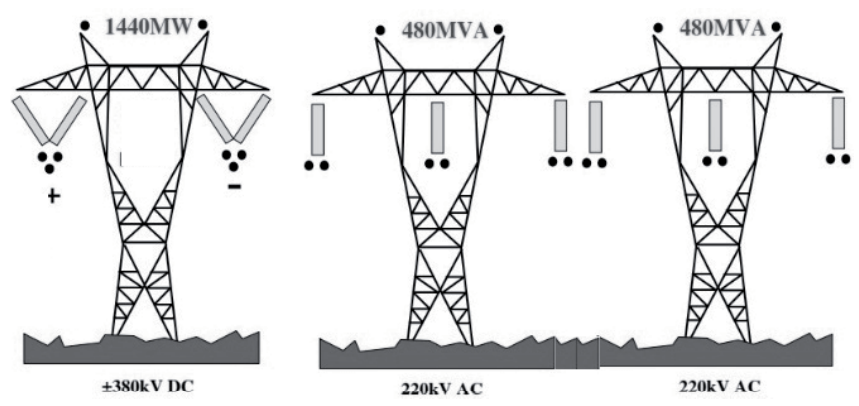

2. irudia. Potentzia eta erredundantzia berdineko KA eta $\mathrm{KZ}$ dorreen arteko konparazioa.

\section{Energia-galerak gutxitu}

HVDC garraio-galerak ia kasu guztietan kapazitate berdineko KA transmisoarenak baino txikiagoak izaten dira aire-lineak erabiltzen direnean eta baita kableak erabiltzen direnean ere. Adibidez 735 kV-eko HVACko $3 \mathrm{GW}$-eko transimiso-sistema batetan, potentzia-galera \% 6, 5ekoa da $1000 \mathrm{~km}$-tan; HVDC sistema batean, ordea, $800 \mathrm{kV}$-eko eta $6.4 \mathrm{GW}$-eko transimiso sistema batean potentzia-galera \% 3, 5 litzateke.

\section{Eragin positiboak sistema elektrikoan}

HVDC sistema asko sare elektriko ezberdinak lotzeko eraiki izan dira.

Lotura hauek aukera ematen dute dagoeneko badauden energia elektrikoa sortzeko plantek era eraginkorragoan lan egiteko, honela, planta berriak sortzeko beharra gutxituz eta ekonomiaren aurrezpena ekarriz.

Ingurumenerako abantailak, berriz, izaten dira, alde batetik, planta berriak eraiki behar ez izatea, eta, bestetik, dagoeneko badaudenak era eraginkorrago batean lan egin ahal izatea. Adibidez, ingurumenerako oso lagungarria izan daiteke generazio hidroelektrikoaren ahalmen handia duen sistema bat eta generazio konbentzionalean oinarrituta dagoen sistemak elkarrekin lotzean. Generazio konbentzionala gutxitu daiteke eskaria-pikoak daudenenan, energia hidroelektrikoa erabiliz piko hori asetzeko, generazio konbentzionalak daudenean era eraginkorragoan lan egiten baitu kontsumo konstantearen bidez.

Ikuspegi ekonomikotik, »break even « deituriko transmisio-distantziatik aurrera, HVDC sistema merkeagoa gertatzen da. Normalean, aire-lineak 
HVDC: Energia elektrikoaren garraioa korronte zuzenaren bidez

erabiltzen direnean 500-800 km inguruan egoten da distantzia hau eta kableak erabiltzen direnean $40-50 \mathrm{~km}$ inguruan.

\subsection{HVDCren desabantailak}

Arestian aipaturiko abantailak handiak izanda ere, HVDC sistemak bere hedapena mugatzen duten desabantailak ere baditu HVAC sistemekin alderatuta. Aipatu ahal diren desabantaila nagusiak hurrengoak dira:

- Potentzia-bihurgailuen kostua: HVDC sistemek KA korrontea artezteko potentzia-bihurgailu erraldoiak behar dituzte. Bihurgailuen kostua oso altua da eta soilik arrazoi teknikoak edo garraio-distantzia luzeegia denean dago justifikatuta kostu hau.

- Potentzia-bihurgailuen galerak: HVDC potentzia-bihurgailuak potentzia-galerak gehitzen dituzte sisteman eta hauek KA eroaleetan gertatzen diren galerak baino txikiagoak izan behar dira aldaketa justifikatzeko. Hala ere, gaur egun potentzia-bihurgailuen potentziagalerak asko murrizten ari dira.

- Fidagarritasuna: HVDC sisteman osagai gehiago daude garraio-sisteman eta, beraz, matxurak gertatzeko probabilitatea handitu egiten da. Honek kezka handia sortzen du sistema elektrikoen operadoreen artean. Nolanahi ere, HVDC sistemak fidagarritasun handia erakusten ari dira orain arte.

- Gaur egun ez dago tentsio altuko korronte zuzeneko etengailurik; momentuz, HVDC sistemek soilik bi punturen arteko lotura egiteko balio dute, eta ezin da erabili sistema multiterminaletan.

\section{NOLA FUNTZIONATZEN DU HVDC SISTEMA BATEK?}

Gaur eguneko HVDC sistema KA/KZ eta KZ/KA konbertsioa egiteko potentzia-elektronikan oinarritzen da, 3 irudian erakusten den bezala. Lehenik eta behin, energia KA moduan sortzen da tentsio maila baxuetan. Gero, tentsio hau transformadore baten bidez handitu egiten da eta artezgailu baten bidez oso balio handiko KZ tentsiora aldatzen da (HVDC) eta honela distantzia oso luzeetan edo kableetan garraiatzen da. Sistemaren beste muturrean aurkako prozesua egiten da tentsio baxuko KA sistemak elikatzeko. Kontuan izan behar da oso tentsio eta korronte balio handietan $(80 \mathrm{kV}$ $800 \mathrm{kV}$ eta $100 \mathrm{~A}-5.000 \mathrm{~A}$ ) egin behar dela konbertsio hau, eta gaur egun erabiltzen diren potentzia handieneko erdieroaleak erabiltzen dira bertan.

Aplikazioaren arabera, bi teknologia nagusi erabiltzen dira gaur egun: HVDC LCC lurrean eta potentzia maila altuenak lortzeko alde batetik, eta HVDC VSC potentzia maila txikiagoetan baina kontrolagarritasun-baldintzak handiagoak direnean, batez ere itsasoan kableak erabili behar dire- 


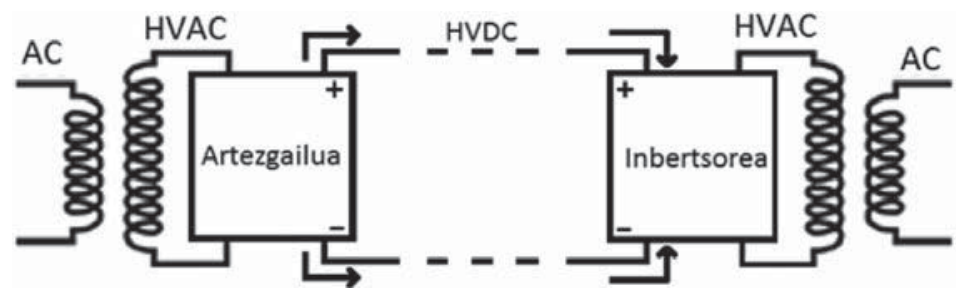

3. irudia. Oinarrizko HVDC sistema.

nean. Sistema hauek 3. irudian agertzen diren artezgailu eta inbertsoreetan erabiltzen diren potentzia-bihurgailutan oinarritzen dira. Hurrengo ataletan bi teknologia hauek deskribatzen dira.

\subsection{HVDC LCC}

HVDC LCC (Line Conmutated Converter) tiristoreen bidezko artezgailuetan oinarritzen da. 4 irudian HVDC LCCn erabiltzen den oinarrizko sistema agertzen da. Oinarrizko bihurgailua 4(a) irudian agertzen den tiristoreen bidez osatutako artezgailu bat da. Artezgailu eta inbertsoreen $\mathrm{KZ}$ aldeko tentsioaren uhin forma 4(b) irudian agertzen da eta tiristoreen desarraila-angeluaren arabera, $\alpha, \mathrm{KZ}$ aldeko tentsioaren batez besteko balioa kontrolatu daiteke $+V$ eta $-V$ balioen artean hurrengo espresioaren arabera

$$
V_{o i}=1.35 V_{L L r m s} \cos \alpha_{i}
$$

Transmisio-linearen mutur bakoitzean dagoen artezgailuen desarrailaangelua kontrolatuz potentzia bi norabideetan bidal daiteke.

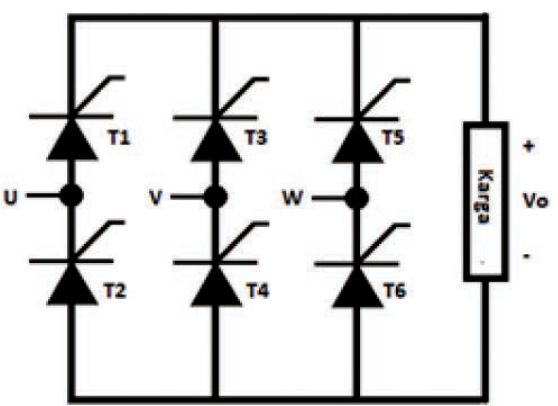

(a)

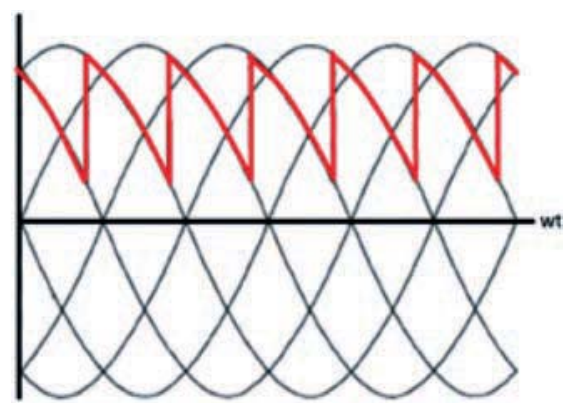

(b)

4. irudia. HVDC LCC oinarrizko potentzia-bihurgailua eta irteerako tentsioaren uhin forma. 
Gaur egun HVDC LCCn erabiltzen diren tiristoreak $8 \mathrm{kV}$ eta $4 \mathrm{kA}$ jasateko gai dira eta 50-60 kHz-ko maiztasunean kommutatzen dira. HVDCn behar diren tentsioak lortzeko tiristoreak seriean konektatu behar dira tentsioa beraien artean era egokian banatzeko. 5 irudian tiristoreak serian konektatuz lortutako «etengailua» ikus daiteke.

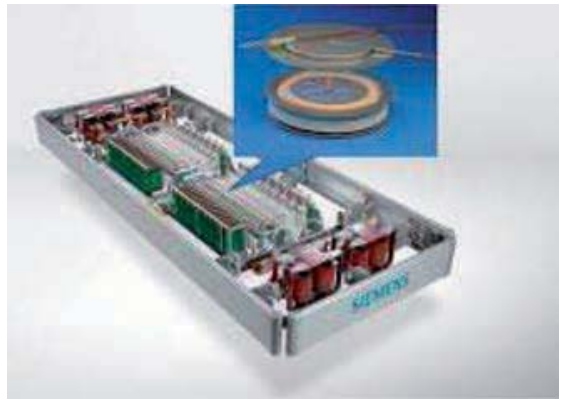

(a)

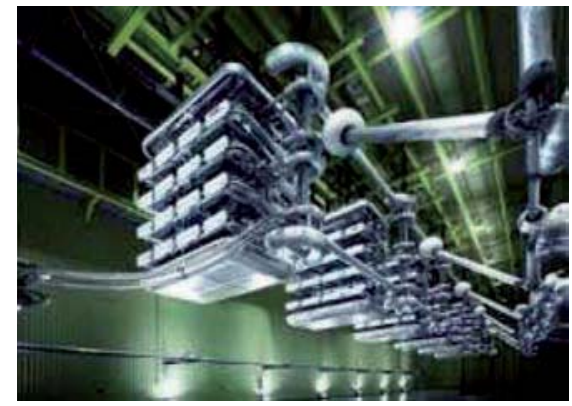

(b)

5. irudia. HVDC LCC sistemetan erabilitako tiristore erdieroaleak eta hauekin osatutako balbulak.

LCC teknologiaren abantaila nagusiak, lortu daitezkeen tentsio eta korronte maila altuak dira. Bestalde, desabantailen artean maiztasun baxuko armonikoak sortzea eta potentzia erreaktiboaren kontsumoa dira.

\subsection{HVDC VSC}

HVDC VSC (Voltage Source Converter) IGBTak (Insulated Gate Bipolar transistor) erabiltzen dituzten inbertsore guztiz kontrolatuetan oinarritzen da [9]. Lehenengo generazioko HVDC VSC sistemak inbertsore trifasikoaren topologian oinarrituta zeuden, baina gaur egun maila anitzeko (MMC edo Modular Multilevel Converter) topologia erabiltzen da galerak gutxitzeko eta distortsio armonikoa gutxitzeko [10, 11]. 6 irudiak lehenengo, bigarren eta azken generazioko KA aldean sortutako uhin formak erakusten ditu. Irudian agerian geratzen da uhin kalitate askoz hobea lortzen dela. Teknologia honek, aldi berean, erdieroale bakoitzaren kommutazio-maiztasuna gutxitzen du, potentzia-galerak gutxituz. Gaur egun, VSC teknologiaren eta LCC teknologiaren potentzia-galerak nahiko antzekoak izatea lortu da.

Gaur egun, HVDC VSCn erabiltzen diren IGBTak $5 \mathrm{kV}$ eta $3 \mathrm{kA}$ jasateko gai dira eta $2 \mathrm{kHz}-\mathrm{ko}$ maiztasunean kommutatu daitezke. 7 irudian HVDC VSCn erabiltzen den oinarrizko sistema agertzen da. 

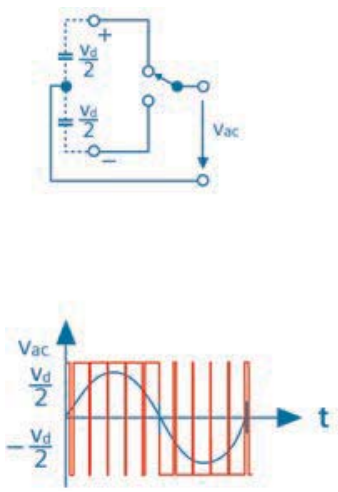
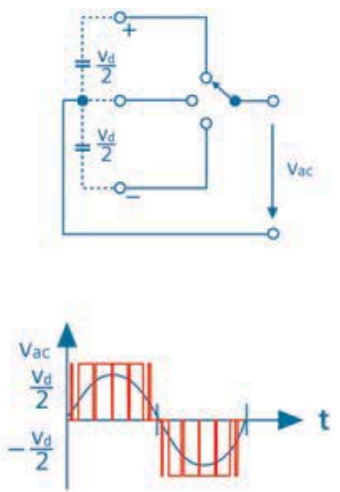
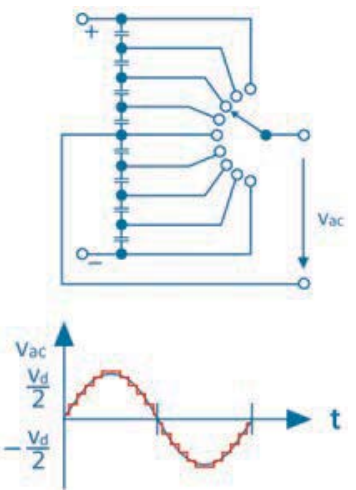

6. irudia. Bi maila, hiru maila eta maila anitzeko VSC bihurgailuak.

Nahiz eta lortzen diren korronte eta tentsio mailak oraindik ez heldu LCC sistemetan lortzen direnetara, potentzia aktibo eta erreaktiboen kontrol osoa eta maiztasun baxuko armonikoen desagerpena direla eta, gero eta sistema gehiagotan erabiltzen den teknolgia da VSC.

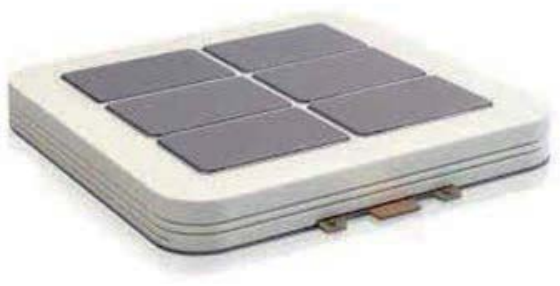

(a)

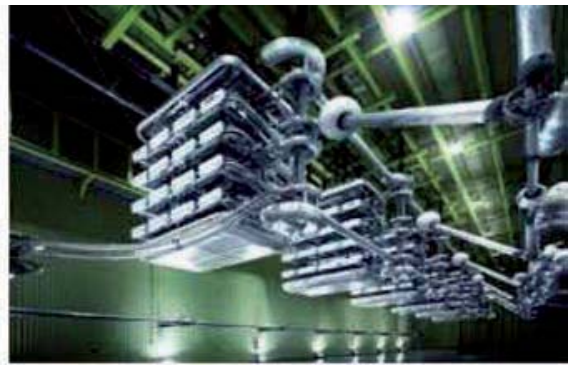

(b)

7. irudia. HVDC VSC sistemetan erabilitako IGBT erdieroaleak eta hauekin osatutako balbulak.

\section{ONDORIOAK}

Nahiz eta KA-transmisioa izan energia elektrikoa garraiatzeko modurik hedatuena, historian zehar KZ-transmisioa hainbat aplikazio berezitan erabilia izan da.

Potentzia-elektronikaren garapenak, batez ere tiristorea asmatu zenetik, bide berriak ireki ditu HVDC sistemak garatzeko. Hasiera baten HVDC sistema hauek oso distantzia luzeko garraioan eta urazpiko kableetan erabiltzen ziren, baina gaur egun, sare elektrikoaren paradigma aldatzen ari 
HVDC: Energia elektrikoaren garraioa korronte zuzenaren bidez

den momentuan eta energia berriztagarriek geroz eta presentzia handiagoa dutenean, tresna garrantzitsua izango da, KZ garraioaren sistema elektriko eraginkorragoa eta ekonomikoagoa lortzeko.

\section{ESKERRAK}

Aurkeztutako lan hau Eusko Jaurlaritzako ikerketa-taldeak laguntzeko IT394-10, UPV/EHU unibertsitateko UFI11/16 eta Etortek FUTUREGRIDS-2020 (IE14-389) ikerketa-proiektuaren fondoen laguntzari esker idatzi da.

\section{BIBLIOGRAFIA}

[1] PIMENOV. 1957. «The work of the Direct Current Institute». IIrningradr, Direct Current, 3. (6), 185-91.

[2] LAMM, U. 1964. «Mercurv-arc valves for high voltage KZ transmission». Proc. IEE, III, (10), 1717-751.

[3] BERNERYD. S. eta FUNKE. 11. 1966. «Design of high voltage mercuryarc valves». IEE conference on High Voltage Transmission, 22.

[4] LIPS. H.P. 1997. «Semiconductor power devices for nse in FIVIX: and FACTS controllers». International Colloquium on HVDC and FACTS, paper 6.8 .

[5] ADAMSON, C. eta HINGORANI N.G. 1960. «High voltage direct current power transmission». Garraway Ltd., London.

[6] KIMBARK. E.W. 1970. «Direct current transmission». Wiley Interscience, New York.

[7] UHLMAN, E. 1975. «Power transmission by direct current». Springer-Verlag, Berlin.

[8] HINGORANI, N.G. 1988. «High power electronics and flexible AC transmission systems». IEEE Power Eng. Rev., July.

[9] FlourentzoU, N.; AGELIDIS, V. eta DEMETRIADES, G. 2009. «VSC-based HVDC power transmission systems: An overview». IEEE Transactions on Power Electronics, vol. 24, no. 3, pp. 592-602.

[10] HUSSENNETHER, V.; RITTIGER, J.; BARTH, A.; WORTHINGTON, D.; Dell'ANNA, G.; RAPETTI, M.; HHNERBEIN, B. eta SIEBERT, M. 2012. «ProjectsBorWin2 andHel- Win1?Large scale multilevel voltage-sourced converter technology for bundling of offshore windpower». Proc. CIGRE Session, Paris, France, vol. B4-306.

[11] PUYU WANG, P.; ZHANG, X.P.; COVENTRY, P.F. eta ZHANG, R. 2016 «Start-Up Control of an Offshore Integrated MMC Multi-Terminal HVDC System With Reduced DC Voltage». IEEE Transactions on Power Systems, vol. 31, No. 4, pp. 2740-2751. 